\title{
ANALYSIS OF THE WHEEL AND RAIL FRICTIONLESS NORMAL CONTACT CONSIDERING MATERIAL PARAMETERS
}

\author{
Yalçın Özdemir, Petr Voltr \\ Jan Perner Transport Faculty \\ Pardubice, Czech Republic \\ yalcinozdemir@anadolu.edu.tr,Petr.Voltr@upce.cz
}

\begin{abstract}
Wheel and rail contact is a transport application of contact mechanics. Outputs of the contact interface are investigated in various perspectives. Examinations of the inputs are generally ignored, but there are assumptions that include material parameters. This study examines the material inputs and assumptions of the previous wheel and rail contact analyses. This study covers the comparison of different elastic material parameters and the effects of the elastic wheel assumption.
\end{abstract}

Keywords: wheel-rail contact, railway, normal contact

\section{Introduction}

Finite element analysis (FEA) is used to research railway structures. With the increase in speed of the railway vehicles, various studies are employed to wheel and rail contact. The examinations are related to either wheel-rail normal contact or rolling contact. Normal contact analyses investigate the normal stress distributions that occur in the contact area of the bodies, whereas rolling contact simulations deal with both normal and tangential contact problems.

Findings of contact interaction are mainly affected by geometry of the bodies [1-3], inputs of material parameters [4] and applied loads. Corresponding studies take various material models, which consist of linear elastic and elastic-plastic material behaviours, into consideration. One of the initial analytic works describing the normal contact problem is the implementation of Hertz [5]. The Hertz theory is based on elastic mechanical properties. Yan and Fisher examined the practicability of the Hertz contact theory in wheel-rail interaction. Material behaviour of the wheel and rail is considered to be linear elastic in which Young's modulus (E) and Poisson's ratio ( $v$ ) is equal to $210 \mathrm{GPa}$ and 0.3 , respectively. Rail material behaviour is assumed as plastic in the elastic-plastic analysis, yet wheel is linear elastic [6]. Elastic characteristics are used either equally or differently for the wheel and the rail in the investigations. 
Zhao and Li developed a 3D model in order to evaluate normal and tangential contact solutions in wheel-rail contact [7] also velocity dependent friction condition [8]. The authors presented frictional wheel-rail rolling contact in elastoplasticity. The 3-D finite element model was set up to simulate rolling contact. In the model, equal values of material parameters were applied to the components by the authors of [9]. Zhao et al. developed the 3D explicit finite element model in order to observe rolling contact with the contaminated rail. There is no difference in material models of wheel and rail in the model $(\mathrm{E}=205.9 \mathrm{GPa}, v=0.3)$ [10]. However, Arslan and Kayabaşı researched the 3D wheel and rail contact model and clarified the flowchart of the 3D model which fits best to reality [11]. In the study, different values of Young's modulus and Poisson's ratio are employed to the bodies. Also, the bilinear elastic-plastic model [12] is different for each component. The material model was used in the other study [13]. Wheel-raillswitch contact was also investigated by researchers [14]. Additionally, analytic contact computations are imported into dynamic simulation of a rail vehicle. Hertz contact theory [5] is commonly used to find contact pressure and geometry of the contact patch, so similar assumptions are used in the dynamic simulations.

The main idea of this study is to develop better evaluation of influences of material inputs in the contact studies. Not only elastic, but also elastic-plastic material properties are considered. The evaluation consists of pressure distribution, dimensions of contact area and maximum pressure values. The results of the study provide an insight into the selection of material parameters for examinations related to wheel and rail contact.

\section{Modelling of wheel and rail contact}

In this study, UIC 60 rail [15] and S1002 [16] wheel theoretical profiles which are regularly used in Europe are utilized. The model of the wheel having a radius of $460 \mathrm{~mm}$ in a longitudinal direction is generated without the hub section due to simplification of the geometry. The length of the rail part is $200 \mathrm{~mm}$ and a portion of the wheel is cut off the whole body of the wheel by a $20^{\circ}$ angle. The generation of a simplified geometry of the wheel and rail is given in Figure 1.
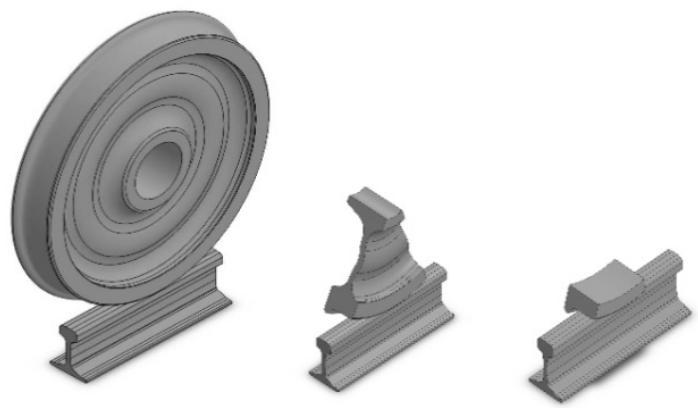

Fig. 1. Generation of simplified wheel-rail contact geometry 
The inclination angle of the rail in railway track geometry could be either $1 / 20$ or $1 / 40$. The rail is inclined at $1 / 40$ (1.432 degree) to obtain realistic track geometry. The reference point of rail that is $14 \mathrm{~mm}$ below from the top of rail (TOR) is determined to specify the rail position. The tape line circle of the wheel is set up $750 \mathrm{~mm}$ from the track centre point to obtain zero lateral shift position of the wheel and centred position of the wheelset, which is visually presented in Figure 2 [17].

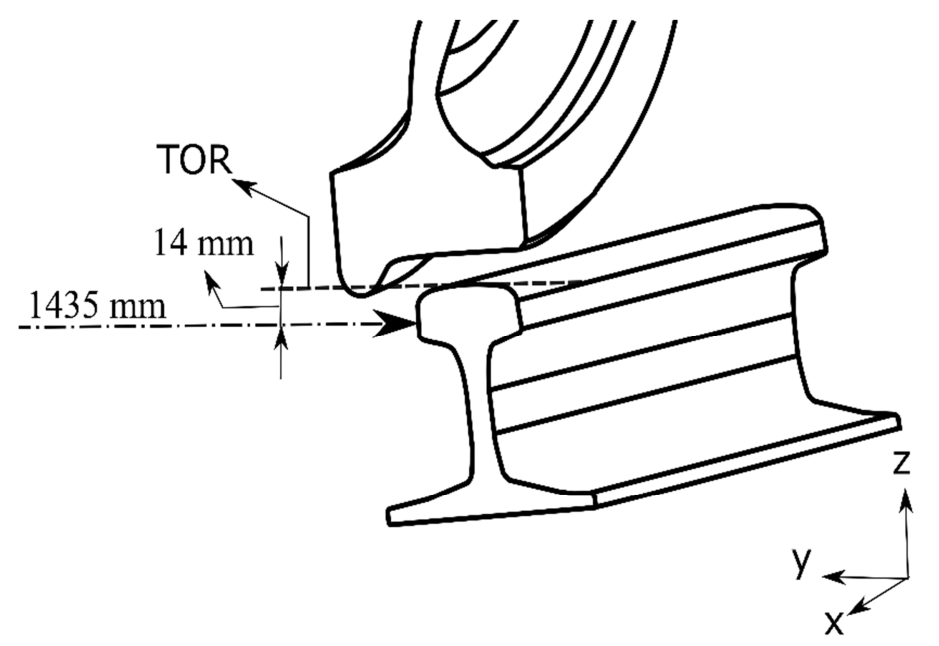

Fig. 2. Non-shifted position of wheelset [17]

\subsection{Material properties of the assembly}

In this study, three different linear elastic material properties of the wheel and rail are examined. Each of the conditions is named as a case of the study. The material parameters (Young's modulus, Poisson's ratio) of the cases used by previous studies in linear elasticity are listed in Table 1, cases 1-3.

Table 1

Material properties of the studied cases [9, 11, 12, 18]; "EP" means elastic-plastic material model whose parameters are specified in Table 2

\begin{tabular}{|c|c|c|c|}
\cline { 2 - 3 } \multicolumn{1}{c|}{} & \multicolumn{2}{c|}{ Young's modulus [GPa] } & \multirow{2}{*}{ Poisson ratio } \\
\cline { 2 - 3 } \multicolumn{1}{c|}{} & wheel & rail & \\
\hline Case 1 & 210.0 & 210.0 & 0.3 \\
\hline Case 2 & 205.9 & 205.9 & 0.3 \\
\hline Case 3 & 210.0 & 200.0 & 0.3 \\
\hline Case 4 & EP & EP & 0.3 \\
\hline Case 5 & 210.0 & EP & 0.3 \\
\hline
\end{tabular}


Arslan and Kayabaşı [11] utilized a bilinear material model of the previous study [12]. Elastic material properties of the study is used in case 3. In order to compare the results of the elastic-plastic wheel-rail (case 4) and the elastic wheelplastic rail (case 5) assumptions, a bilinear material model is defined. The material model for the comparative study is listed in Table 2. Zhao and Li [9] determined elastic-plastic material model in reference to literature $[19,20]$. The difference in the case 4 and 5 is material properties of the wheel part. The material model of the rail is elastic-plastic in both cases, but the wheel part is different. One of the cases assumes elastic wheel material, while the other one is elastic-plastic material property for wheel.

Table 2

Parameters of elastic-plastic material model $[9,19,20]$

\begin{tabular}{|c|c|}
\hline Parameters & Values \\
\hline Young's modulus & 210 \\
\hline Poisson's ratio & 0.3 \\
\hline Density & $7800 \mathrm{~kg} / \mathrm{m}^{3}$ \\
\hline Yield strength & $500 \mathrm{MPa}$ \\
\hline Tangent modulus & $21 \mathrm{GPa}$ \\
\hline
\end{tabular}

\subsection{Procedure of finite element analysis}

The numerical simulation is performed through ABAQUS ${ }^{\mathrm{TM}}$ [21]. Simplified geometry of the wheel and rail is imported into the FEA program. A reference point is placed at the centre of the wheel axle. The connection between the reference point and inner surface of the wheel is achieved with a type of constraint. The axle load is applied to the reference point in the z-axis. The bottom of the rail is restricted to vertical motion via a fixed type of boundary conditions. The right and left sides of the wheel are constrained into lateral and longitudinal directions due to profile of the wheel. The profile of the wheel is conical (i.e. not straight and level in the lateral direction), so the profile brings about undesired motions during simulation. The density of the mesh structure is locally increased in the contact region of the assembly. A solid C3D8R reduced integral element is used for meshing process [21]. Various edge size of the element is applied to model and values of the maximum contact pressure are compared in each other. $0.5 \mathrm{~mm}$ mesh size is chosen for edge length of the element in the contact region. Meshed bodies are illustrated in Figure 3.

Normal contact definition at the contact interface is defined in the ABAQUS ${ }^{\mathrm{TM}}$. The coefficient of friction is not taken into account, since there is no tangential contact definition in the interaction properties. The effect of gravitational force is not considered in the simulation [21]. 


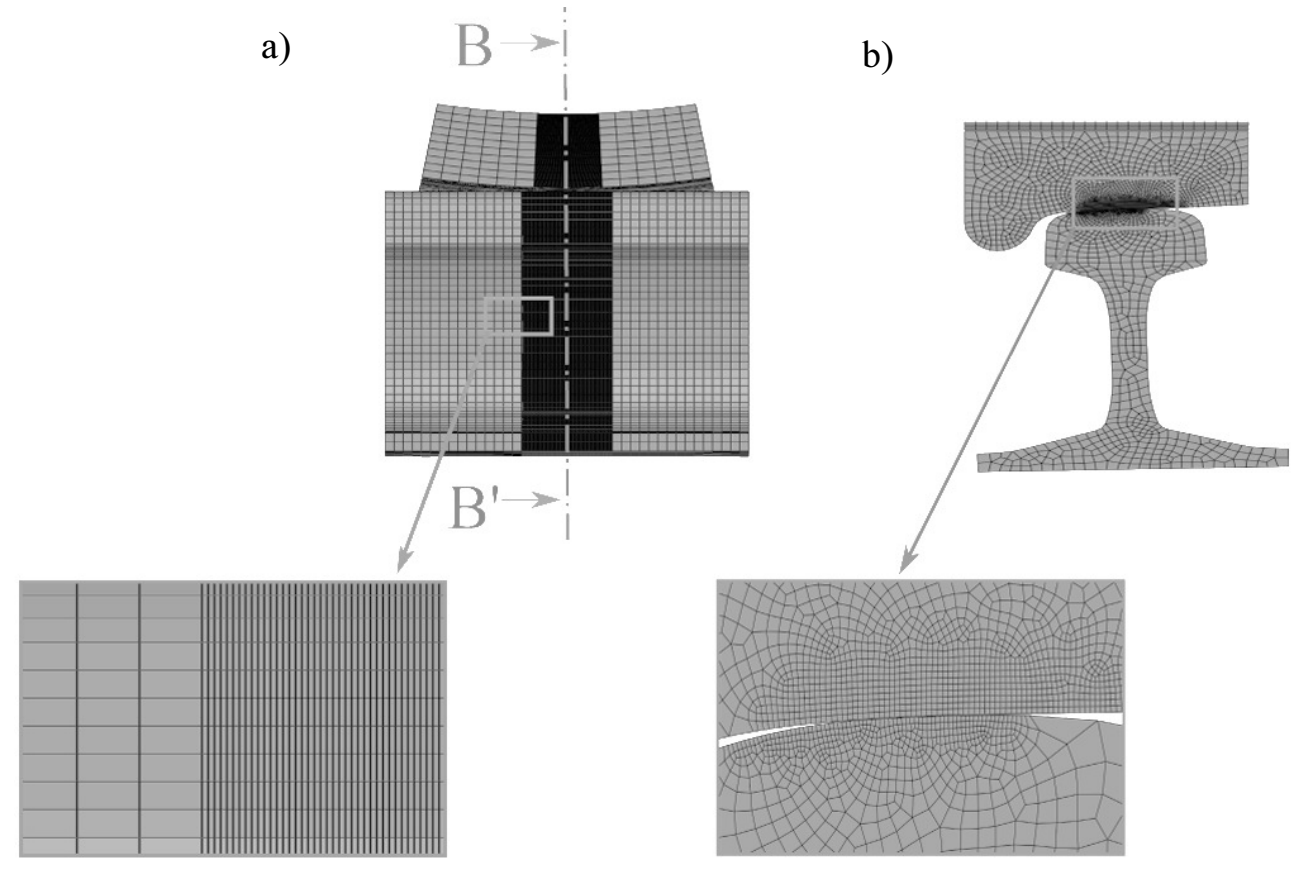

Fig. 3. Illustration of the meshed bodies: a) side view of the assembly, b) front view of the assembly

\section{Results}

\subsection{Elastic material behaviour}

Firstly, outputs of the elastic analysis (cases 1-3) are compared to each other according to maximum contact pressure and pressure distribution, as well as the total contact area. The cross-section view of case 1 is shown in Figure 4. Equivalent stress distribution of the cross-section view of wheel and rail contact is visualized with a stress legend. As it appears in the cross-sectional view, the maximum stress level is observed under the surface of the wheel and rail. There are two peaks in the observed surface stress distribution, which means that the contact patch is composed of two sub-regions. This situation is not compatible with Hertzian contact geometry.

Initial comparison consists of the pressure distribution which is determined by obtaining nodal results on the undeformed contact patch. The top view of the patch is illustrated in Figure 5. Pressure distribution at the centre of the contact patch is obtained in the lateral direction (A- $\mathrm{A}^{1}$ direction). The distribution is given in Figure 6 . There is no significant difference among the cases. 


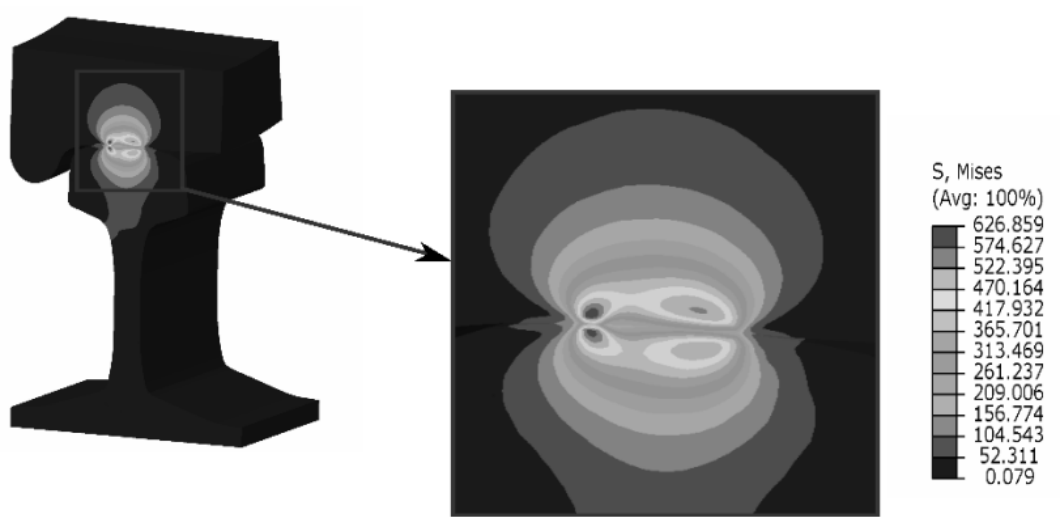

Fig. 4. Stress distribution in cross-sectional view of wheel and rail for case 1

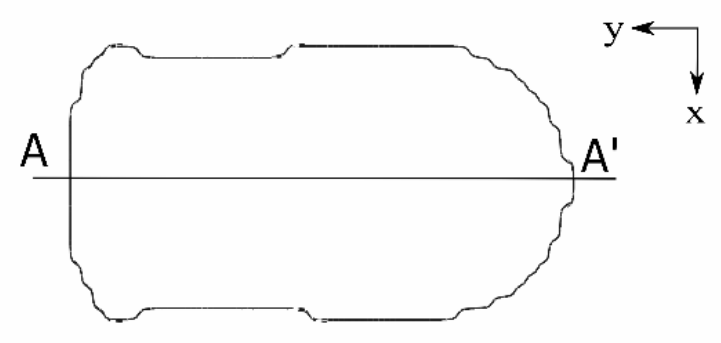

Fig. 5. Top view of the contact patch

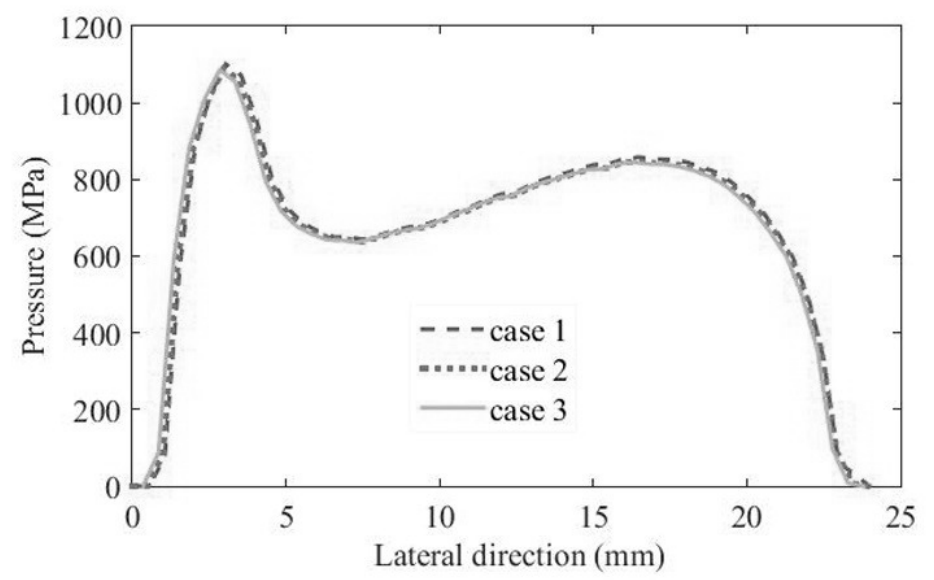

Fig. 6. Pressure distribution in lateral cross-section for cases 1, 2 and 3

The maximum pressure levels and total contact area of the three cases are listed in Table 3. Total contact area is acquired thanks to ABAQUS ${ }^{\mathrm{TM}}$. The maximum pressure level of case 1 is bigger than those for case 3 , but that is not remarkable 
since the values differ by no more than $1.4 \%$. The difference between these cases depends on Young's modulus of the rail which is lower than in case 1.

Table 3

Results of cases 1-3

\begin{tabular}{|c|c|c|}
\cline { 2 - 3 } \multicolumn{1}{c|}{} & $\begin{array}{c}\text { Contact area } \\
{\left[\mathrm{mm}^{2}\right]}\end{array}$ & $\begin{array}{c}\text { Max. contact pressure } \\
{[\mathrm{MPa}]}\end{array}$ \\
\hline Case 1 & 234.175 & 1101 \\
\hline Case 2 & 235.915 & 1090 \\
\hline Case 3 & 236.153 & 1086 \\
\hline
\end{tabular}

\subsection{Elastic-plastic material behaviour}

The second part of the results show the variations between case 4 and 5 (Table 4). Elastic wheel assumption gives rise to higher maximum pressure values in the contact interface. Elastic mechanical properties of case 4,1 and 5 are the same. On account of that, maximum pressure level of case 5 is close to level of case 1 . However, there is a difference due to plasticity.

Table 4

\begin{tabular}{|c|c|c|}
\multicolumn{1}{c}{} & \multicolumn{2}{c|}{ Results of cases 4 and 5 } \\
\cline { 2 - 3 } \multicolumn{1}{c|}{} & $\begin{array}{c}\text { Contact area } \\
{\left[\mathrm{mm}^{2}\right]}\end{array}$ & $\begin{array}{c}\text { Max. contact pressure } \\
{[\mathrm{MPa}]}\end{array}$ \\
\hline Case 4 & 235.675 & 1015 \\
\hline Case 5 & 234.925 & 1052 \\
\hline
\end{tabular}

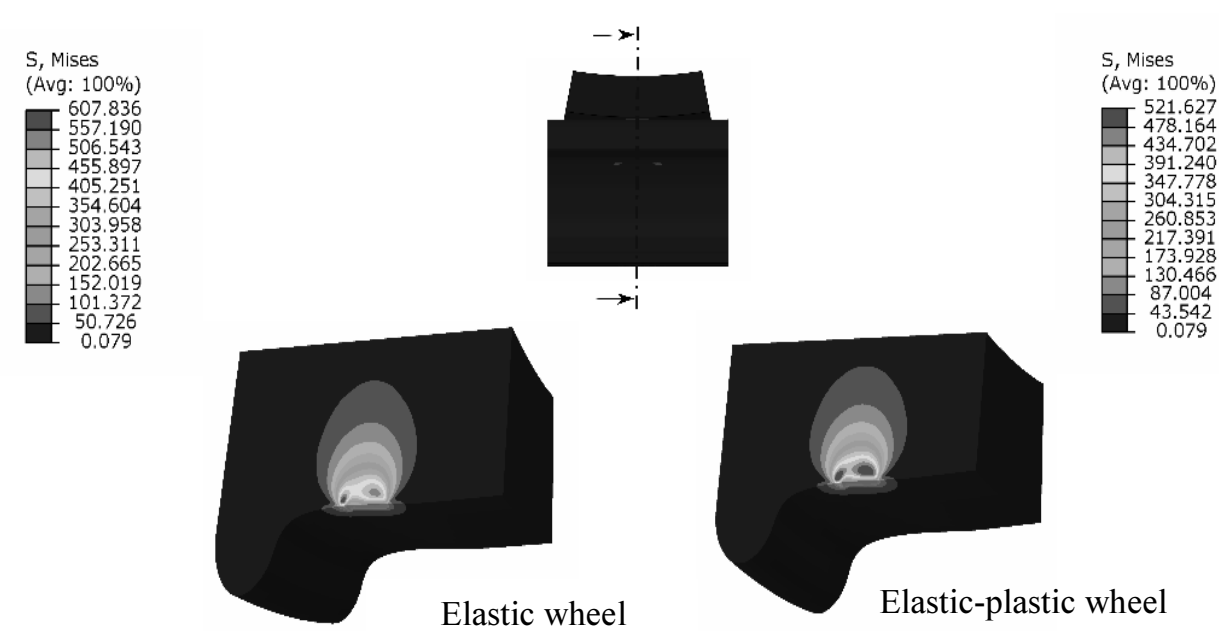

Fig. 7. Stress distributions of wheel bodies in case 4 (right) and case 5 (left) 
At the point where stress distributions of the wheel bodies of cases 4 and 5 are compared (Fig. 7), the distributions do not agree with each other. The difference stems from plasticity. Case 5 has elastic wheel assumption, so plastic strain does not occur in the body of the wheel.

A note should be made on the extent of plastic deformation. Yield strength of the material is set to $500 \mathrm{MPa}$, whereas the calculated wheel-rail contact pressure goes beyond by twice that value. That is, however, not decisive for plasticity. Equivalent tensile stress determined by following von Mises criterion, i.e.

$$
\sigma_{e}=\sqrt{\frac{1}{2}\left(\left(\sigma_{1}-\sigma_{2}\right)^{2}+\left(\sigma_{2}-\sigma_{3}\right)^{2}+\left(\sigma_{3}-\sigma_{1}\right)^{2}\right)}
$$

$\left(\sigma_{1}, \sigma_{2}, \sigma_{3}\right.$ meaning the principal stresses) does not exceed the yield stress value at the surface and there is no plastic deformation of the surface layers in the contact area. The zone of plastic deformation is limited to the inside of the material for the investigated case. It would shift/extend towards the surface if the compressive force was higher or the tangential force was also present [22].

\section{Conclusions}

Findings of the study may be summarized as follows;

1. Material inputs of cases 1,2 and 3 have got no remarkable effects on the results. Young's modulus of steel, in the range that can be considered for wheel and rail, makes only a small variation in the resulting stresses and the contact area size; selection of different values for the wheel and the rail also has little effect.

2. Plastic deformation changes the outputs of the contact interface. If the elasticplastic material model is considered, a plastic zone is formed under the surfaces of the bodies. In the investigated cases (frictionless contact with maximum elastic pressure about $1100 \mathrm{MPa}$ ), however, the extent of plastic deformation does not reach to the surface and the maximum contact pressure is only a little lower than for the linear elastic case. The influence of plasticity would be higher if the yield strength was lower or the loading was higher. Additionaly, if the yield strength of the wheel is higher than that of the rail, outputs of the analysis would be dissimilar from previous results.

3. Elastic wheel assumption gives rise to differences, which is obviously understandable from maximum contact pressure levels, in the normal contact problem. Researchers who are interested in wheel-rail contact, rolling contact fatigue etc. should consider this effect.

\section{References}

[1] Srivastava J.P., Sarkar P.K., Ranjan V., Contact stress analysis in wheel-rail by Hertzian method and finite element method, Journal of The Institution of Engineers (India): Series C 2014, 95, 4, 319-325. 
[2] Telliskivi T., Olofsson U., Contact mechanics analysis of measured wheel-rail profiles using the finite element method, Proceedings of the Institution of Mechanical Engineers Part F: Journal of Rail and Rapid Transit 2001, 215, 2, 65-72.

[3] Sladkowski A., Sitarz M., Analysis of wheel-rail interaction using FE software, Wear 2005, 258, 7-8, 1217-1223.

[4] Ashofteh R.S., Mohammadnia A., Stress analysis in the elastic-plastic analysis of railway wheels, IJR International Journal of Railway 2014, 7, 1, 1-7.

[5] Hertz H., Über die Berührung fester elastischer Körper, Journal für die reine und angewandte Mathematik 1882, 92, 156-171.

[6] Yan W., Fischer F.D., Applicability of the Hertz contact theory to rail-wheel contact problems, Archive of Applied Mechanic 2000, 70, 4, 255-268.

[7] Zhao X., Li Z., The solution of frictional wheel-rail rolling contact with a $3 \mathrm{D}$ transient finite element model: Validation and error analysis, Wear 2011, 271, 1-2, 444-452.

[8] Zhao X. Li Z., A solution of transient rolling contact with velocity dependent friction by the explicit finite element method, Engineering Computations 2016, 33, 4, 1033-1050.

[9] Zhao X., Li Z., A three-dimensional finite element solution of frictional wheel-rail rolling contact in elasto-plasticity, Proceedings of the Institution of Mechanical Engineers, Part J: Journal of Engineering Tribology 2015, 229, 1, 86-100.

[10] Zhao X., Wen Z., Zhu M., Jin X., A study on high-speed rolling contact between a wheel and contaminated rail, Vehicle System Dynamics: International Journal of Vehicle Mechanics and Mobility 2014, 52, 10, 1270-1287.

[11] Arslan M.A., Kayabaşı O., 3-D rail-wheel contact analysis using FEA, Advances in Engineering Software 2012, 45, 1, 325-331.

[12] Sellgren U., Telliskivi T., Olofsson U., Kruse P., A tool and a method for FE analysis of wheel and rail interaction, Proceedings of the ANSYS Conference, Pittsburgh 2000.

[13] Aalami M.R., Anari A., Shafighfard T., Talatahari S., A robust finite element analysis of the rail-wheel rolling contact, Advances in Mechanical Engineering 2013, 5, 9.

[14] Wiest M., Kassa E., Daves W., Nielsen J.C.O., Ossberger H., Assessment of methods for calculating contact pressure in wheel-rail/switch contact, Wear 2008, 265, 9-10, 1439-1445.

[15] 13674-1:2011 EN, PN. Railway applications-Track-Rail-Part 1, 2011.

[16] 510-2 UIC Code Trailing Stock: Wheels and Wheelset. Conditions Concern, 2004.

[17] CSN 736360-1:2008, Czech Institute for Normalization, Praha 2008.

[18] Zhao X., Wen Z., Wang H., Jin X., Zhu M., Modelling of high-speed wheel-rail rolling contact on a corrugated rail and corrugation development, Journal of Zhejiang University-SCIENCE A (Applied Physics \& Engineering) 2014, 15, 12, 946-963.

[19] Esveld C., Modern Railway Track, 2nd ed., MRT Productions Zaltbommel, The Netherlands, 2001, 296-298.

[20] Johansson G., Ahlström J., Ekh M., Parameter identification and modeling of large ratcheting strains in carbon steel, Computers \& Structures 2006, 84, 15-16, 1002-1011.

[21] ABAQUS 6.13 user manual, www.3ds.com

[22] Johnson K., Contact Mechanics, Cambridge University Press, 1985. 